\title{
Does economic development widen or narrow the gap of public health service utilization among different subgroups of internal migrants? Evidence from the China Migrant Dynamic Survey in 2017
}

\author{
Zhen Yang \\ Tongji University School of Medicine \\ Chenghua Jiang ( $\nabla$ jchtongji@163.com ) \\ Tongji University
}

\section{Research}

Keywords: Internal Migrants, Social Capital, Migration Range, Regional Economic Development Level, Socioeconomic Status, Public Health Services, Cross-sectional Study

Posted Date: May 5th, 2021

DOI: https://doi.org/10.21203/rs.3.rs-486787/v1

License: (c) (i) This work is licensed under a Creative Commons Attribution 4.0 International License. Read Full License 


\section{Abstract \\ Background}

China is promoting the equalization of National Essential Public Health Services (NEPHS) for the internal migrants (IMs). Studies have analyzed the impact of migration range (MR) and regional economic development level (REDL) on the IMs' NEPHS utilization (NEPHSU), but no studies have explored the interaction of MR and REDL on it.

\section{Methods}

Data from the China Migrant Dynamic Survey of 2017, involving 122656 IMs. Per capita GDP was set as the indicator for REDL, and 28 provinces were divided into three groups according to REDL: affluent, medium and poor. The MR was divided into inter-province and intra-province, and social capital (SC) was distinguished into cognitive (CSC) and structural social capital (SSC). Awareness of NEPHS (ANEPHS) and establishment of health record (EHR) were selected as indexes of NEPHSU. Multiple line charts and hierarchical logistic regression were used to investigate the interaction of MR, REDL and SC on NEPHSU.

\section{Results}

(1) The socioeconomic status (SES) and social capital (SC) of inter-provincial IMs were significantly lower than those of intra-provincial IMs, and the gap was most prominent in affluent areas. (2) From low to high, the NEPHSU of inter-provincial IMs was ranked as affluent, medium and poor, while the corresponding order of intra-provincial IMs was medium, poor and affluent areas, and the gap of NEPHSU between inter-provincial and intra-provincial IMs was the largest in affluent areas. (3) SC could significantly promote the IMs' NEPHSU, but there was a gap between inter-provincial and intra-provincial IMs, and the gap was the largest in affluent areas.

\section{Conclution:}

REDL can significantly affect the gaps of SES and SC among subgroups of IMs with different MR. Interprovincial migrants in affluent areas have relatively lower SES and SC, which may be a major barrier to their access to NEPHS, and the government should pay special attention to this vulnerable group when promoting equalization of NEPHS for IMs.

\section{Background}

Over the past three decades, social change has led to unprecedented massive internal migration in China. An increasing number of people leave their original places of residence to work and live in other provinces or cities to improve their lives, such people are called internal migrants (IMs). The number of IMs 
exceeded 240 million in 2017 [1]. IMs are vulnerable to social exclusion in their destinations [2], which prevents them from accessing local National Essential Public Health Services (NEPHS) as equitably as local residents [3]. Social exclusion has become an important risk affecting the health of IMs [4].

However, the situation has been improving in the past decade. China initiated the NEPHS projects in 2009, which required Community Health Centers to provide NEPHS to all residents in their area, including IMs that have lived there for more than six months [5]. Since then, the National Health Commission (NHC) has successively introduced major measures to strengthen the equalization of NEPHS for the IMs [6-8]. Although NEPHS deployment level has risen rapidly in recent years [9], there is still a significant gap in the national target, and the underlying factors need to be revealed. Some recent studies have confirmed that gender, education, community type, migration range (MR) and regional economic development level (REDL) have significant impacts on the IMs' NEPHSU [10-15].

MR and REDL are important variables reflecting regional differences in the NEPHSU of IMs. Some studies have pointed out that the NEPHSU level of trans-provincial migrants is low $[9,10,13-15]$, and some studies have suggested that the NEPHSU level of migrant population in affluent areas is low [12-15]. However, there is no study to find out whether the interprovincial migrants in affluent areas have lower NEPHSU level, and the interaction between MR and REDL has been ignored. Existing studies on MR and REDL have two doubts: First of all, existing studies have divided China into three geographical regions: the eastern, central and western region. Data show that the eastern region has the lowest NEPHSU level of migrant population. However, most provinces in the eastern region are economically developed, so these studies infer that the NEPHSU level of the migrant population in the richer regions is lower, which is not rigorous. Secondly, when comparing the NEPHSU levels of intra-provincial and inter-provincial migrant population, existing studies did not exclude Beijing, Tianjin and Shanghai. However, these three cities only have an inter-provincial migrant population, which may lead to bias if they were not excluded. In addition, the analysis shows that the demographic variables are limited in explaining the variation in the NEPHSU of the migrant population, and new variables must be introduced.

Social capital (SC) is an important social determinant of health, and access to health services has been suggested as a pathway by which SC influences health outcomes [16]. Different types of SC affect health services utilization by influencing the availability of health services in communities, the availability and effectiveness of outreach resources between health-care providers and communities they serve, and careseeking behavior of individuals in those communities[17]. Migration means a loss of the original social network and a reduction of social participation in the new environment [18]. However, the SC that migrants have in their destination is more important for their access to local health services $[19,20]$. SC is more often used to discuss its influence on IMs' health outcomes in China[20-25], while ignoring its value in the accessibility of health services. Guo et al. [26] had pointed out that lack of information is the biggest obstacle to IMs accessing NEPHS in China. From the social resource perspective, SC can influence health information through three mechanisms: increased information exposure, enhanced seeking abilities, and reinforced health culture or norms embedded in social networks [27]. Therefore, SC may play an important role in IMs' access to NEPHS. 
Few studies have made explorations in this area. Hou et al. [28] revealed that individual structural SC has a significant positive effect on NEPHSU, while Zeng et al. [29] pointed that SC can moderate the negative effect of social discrimination on IMs' health service utilization. After reviewing the existing studies, there are at least two limitations that need to be improved: (1) Some studies have pointed out that the SC of IMs is inferior to that of local people [30,31], but few studies have revealed the differences of SC among different subgroups of migrant population, and our understanding of the distribution of SC of IMs is still not enough. (2) Not everyone has access to the same sources of SC and not everyone will benefit in the same way[32]. Carpiano and Moore [33] suggested that SC and health knowledge base can be better served by asking three foundational questions of (a) how, (b) for whom, and (c) in which contexts does SC work or operate, rather than focusing primarily on whether SC provides some universal health benefit. However, there is still a lack of research on question $b$ and $c$ in China.

Based on the existing research analysis, we believe that there may be a significant interaction effect between the MR, REDL, SC and NEPHSU of the IMs. This study focuses on testing three hypotheses: (1) Cheng et al. [34] suggested that socioeconomic status (SES) between registered population and migrant population as well as within the migrant population are highly heterogeneous. This difference may be influenced by the interaction between MR and REDL. (2) Since MR and REDL can significantly affect an individual's SES, There is a strong correlation between SES and SC, so the social capital of the migrant population may also be influenced by the interaction between MR and REDL. (3) Given that the relationship between SC and health can be moderated by SES, there may be a significant interaction among MR, REDL, SC and NEPHS utilization. Our findings could help deepen the understanding of the relationship between SC and access to public heath services for IMs, and also provide a reference to the improvement on relevant policies of the Chinese government and other developing countries.

\section{Methods}

\section{Data}

The data was obtained from the China Migrant Dynamic Survey (CMDS) in 2017 provided by the Migrant Population Service Center. CMDS is an annual national sample survey of the internal migrants organized by the NHC from 2009, with an annual sample size of approximately 200,000 households. CMDS adopts the layered, multi-stage, and proportional to scale PPS (Probability proportional to size) sampling method. This study adopted the individual questionnaire A of CMDS, which was uniformly printed and distributed by the NHC. The questionnaire A includes basic information about respondent's demography, perception of the destination, the state of social interaction, and utilization status of NEPHS, etc. Full-time investigators collected the questionnaire data through household interviews, and each respondent gave informed consent before commencing the interview. Dates were entered through the migrant population health and household planning dynamic monitoring system, input data was subjected to multiple checks to ensure quality. The respondents consisted of IMs aged 15-59 living in the destination for more than one month. 
In this study, the inclusion conditions were set as "18-59 years of age, residence duration more than one year. Because Beijing, Tianjin and Shanghai do not have an interprovincial migrant population, it is impossible to compare the differences between the intra-provincial and interprovincial groups, so the samples from these three cities were excluded. After the quality audit, 122665 people were finally included in this study. In addition, we introduce GDP per capita to reflect the REDL of each provincial region, and GDP per capita is based on 2017 data from the National Bureau of Statistics.

\section{Measurement}

\section{Utilization of NEPHS}

Awareness of NEPHS (ANEPHS) is a prerequisite for NEPHSU [26]. ANEPHS was set as a dependent variable. The question was "Have you heard of the NEPHS" and the answer was "yes or no". Another outcome variable is establishment of health records (EHR). The question was "Have you established health records at the destination" and the answer was "yes or no". EHR is one of the service priorities and reflects the actual use of services by the migrant population.

\section{Demographic variables}

Demographic variables included in this study included gender, community type, MR, and REDL. The community types were divided into urban and rural areas. The MR was divided into group inter-province and intra-province. According to the provincial GDP per capita division published by the National Bureau of Statistics in 2017, the top 10 were classified as group affluent (Beijing, Tianjin and Shanghai were excluded), the middle 10 as group medium, and the last 11 as group poor.

SES

Education and household income are often used as indicators of SES. In this study, education was divided into four categories according to years of education: $\leq 6$ years, 7-9 years, 10-12 years and $>12$ years. Considering that relative income can better reflect the impact of income gap when regional economic development levels are unbalanced [35], the household income in this study is in the form of relative income, that is, the annual household income divided by the per capita GDP of the locality.

$S C$

SC refers to the resources and benefits received through connections with others, either as individuals or groups, it can be distinguished into two dimensions: SSC and CSC [16]. SSC refers to the presence of formal opportunity structures or activities in which individuals build or strengthen their social connections; CSC generally refers to individuals' perceptions, beliefs, and attitudes toward their social surroundings, with corresponding measures focused mainly on the concepts of generalized and particularized trust [36]. In this study, SC was limited to the destination, and it was a localized SC that reflects the social resources available to the migrant population there. 
The SSC of this survey included civic participation and social participation in the destination. Questions of the former were: "since 2016, have you made suggestions to your unit/community/village or supervised the unit/community/village affairs management", "since 2016, have you participated in property donation, blood donation, volunteer activities, etc.", "since 2016, have you reported the situation/put forward policy suggestions to relevant government departments in various ways ", "since 2016, have you posted online comments on national affairs and social events or participated in related discussions", "since 2016, have you participated in party/youth league organization activities and party branch meetings". The answer to each question was " $1=$ no, $2=$ occasionally, $3=$ sometimes, and $4=$ often", the score ranged from 5 to 20 . The question of social participation was "Have you participated in any of the following activities in the past year: trade unions, volunteer associations, homecoming associations, fellow-students association, home town chamber of commerce, others", the score ranged from 0 to 7. According to the distribution characteristics of scores, civic participation was integrated into 5 levels: 1 (5 points), 2 (6 points), 3 (7 points), 4 (8 points), 5 (9-20 points). Social participation was also integrated into 5 levels: 1 (0 points), 2 (1 points), 3 ( 2 points), 4 (3 points), 5 (4-6 points). The spearman correlation coefficient of civic participation and social participation was $0.366(p<0.001)$, and the SSC grade can be obtained by adding the two grades, and 7 grades were: 1 (2 points), 2 (3 points), 3 (4 points), 4 (5 points), 5 (6 points), 6 (7 points), 7 (8-10 points).

The CSC generally refers to IMs' perceptions, beliefs, and attitudes toward their destination, with corresponding measures focused mainly on the concepts particularized trust. There were 5 questions in the survey: "I like the city/place I live now", "I am concerned about the changes in the city/place I live now", "I am very willing to blend with the local people and become a part of them", "I think the local people are willing to accept me as a part of them", "I feel locals look down on outsiders". The answer to each question was " 1 =totally disagree, $2=$ disagree, $3=$ =basically agree, and $4=$ totally agree". The $a$ of CSC was 0.779. According to the distribution of scores, CSC was divided into 7 levels: 1 (5-14 points), 2 (15 points), 3 (16 points), 4 (17 points), 5 (18 points), 6 (19 points), 7 (20 points).

\section{Statistical analysis}

SPSS 22.0 was used for data analysis. First of all, we calculated the mean value and standard deviation of the included continuous variables, and counted the frequency distribution of different subgroups of classified variables (Table 1), which comprehensively described the basic situation of the sample. Secondly, we took household income, education and SC as dependent variables, MR and REDL as factors to conduct interaction analysis (Table 2) to verify hypothesis 1 and 2 . Thirdly, we used univariate analysis to verify whether gender, education, community type, MR, REDL and SC had significant impacts on ANEPHS and EHR one by one. The verification methods included cross-table, chi-square test and independent sample t test. Fourthly, we used multiple line charts to visually present the cross relationship among MR, REDL, SC and NEPHSU (Figure 1-4). Finally, we used gender, education, community type and household income as the control variables, MR and REDL as the moderating variables, and ANEPHS and EHR as the dependent variables for a hierarchical logistic regression analysis (Table 3-4) to discuss the degree and direction of the interaction among MR, REDL, SC and NEPHSU. 


\section{Results}

\section{Characteristics of the sample}

The IMs' mean residence duration was $(7.01 \pm 5.796)$ years of the sample. The average household income coefficient was $(1.54 \pm 1.201)$. The level of NEPHSU of the IMs was not high, and the rate of ANEPHS was $62.2 \%$, while the rate of EHR was only $32.1 \%$. Demographically, the proportion of group male, low education, urban and intra-province was higher, while the regional distribution of the sample is more balanced. The SC of the IMs is characterized by high CSC and low SSC. The proportion of CSC in the low group (Level 1 ) is only $15.6 \%$, while that in the high group ( $\geq 16$ points) was $57.0 \%$. The proportion of SSC in low subgroup (2 points) reached $38.3 \%$, this means that more than one third of IMs had neither civic nor social participation in the past year.

\section{Impact of MR and REDL on SES, SC and NEPHSU}

We analyzed the impacts of MR and RED on IMs' SES and SC (Table 2). In the three groups of REDL, the average educational level of the inter-provincial IMs was lower than that of the intra-provincial IMs, and the gap in group affluent was the largest (-0.32) while the difference in group poor was the smallest $(-0.13)$. The gaps of household income between the inter-province and intra-province group were different in the three groups of REDL, and gaps of the group affluent, medium and poor were $-0.08,0.38$ and 0.39 , respectively. Multivariate ANOVA showed that MR and REDL had significant effects on education $(F=114.377, p<0.001)$ and household income $(F=382.699, p<0.001)$. Among three groups of REDL, the SC of group inter-province was lower than that of group intra-province. The gaps between the group interprovince and intra-province in the three REDL groups were $-0.83,-0.04$ and -0.36 , respectively. The gaps in SSC were $-0.32,-0.19$ and -0.13 . The interactions of MR and REDL on CSC $(F=369.360, p<0.001)$ and SSC were significant. The rate gaps of ANEPHS in group affluent, medium and poor were $-10 \%,-3 \%$ and $-4 \%$, respectively. The corresponding gaps in EHR were about $-10 \%,-2 \%$ and $-5 \%$, respectively. The interactions of MR and REDL on ANEPHS $(F=68.081, p<0.001)$ and EHR $(F=67.457, p<0.001)$ were significant.

Table 1 Characteristics of the sample, in 2017, China ( $N=122665)$. 


\begin{tabular}{|c|c|c|c|c|c|c|c|}
\hline Variables & Subgroups & $\mathrm{N}$ & $\%$ & Variables & Subgroups & $\mathrm{N}$ & $\%$ \\
\hline \multirow[t]{2}{*}{ ANEPHS } & Yes & 76247 & 62.2 & \multirow[t]{7}{*}{ CSC } & Level 1ه5-14 & 19089 & 15.6 \\
\hline & No & 46418 & 37.8 & & Level $2 \bowtie 15$ & 33643 & 27.4 \\
\hline \multirow[t]{2}{*}{ EHR } & Yes & 39357 & 32.1 & & Level 3₫16 & 15264 & 12.4 \\
\hline & No & 83308 & 67.9 & & Level $4 \llbracket 17$ & 11417 & 9.3 \\
\hline \multirow[t]{2}{*}{ Gender } & Male & 63375 & 51.7 & & Level 5₫18 & 10410 & 8.5 \\
\hline & Female & 59290 & 48.3 & & Level 6ه19 & 16872 & 13.8 \\
\hline \multirow[t]{4}{*}{ Education (year) } & $\leq 6$ & 20635 & 16.8 & & Level 7『20 & 15970 & 13.0 \\
\hline & $7-9$ & 55264 & 45.1 & \multirow[t]{9}{*}{ SSC } & Level $1 \rrbracket 2$ & 46992 & 38.3 \\
\hline & $10-12$ & 27150 & 22.1 & & Level 2ه3 & 27468 & 22.4 \\
\hline & $>12$ & 19616 & 16.0 & & Level 3₫4 & 18935 & 15.4 \\
\hline \multirow[t]{2}{*}{ Community type } & Urban & 92356 & 75.3 & & Level $4 \llbracket 5$ & 11673 & 9.5 \\
\hline & Rural & 30309 & 24.7 & & Level 5ヌ6 & 7571 & 6.2 \\
\hline \multirow[t]{2}{*}{ Migration range } & inter-province & 71093 & 58.0 & & Level 6ه7 & 4723 & 3.9 \\
\hline & intra-province & 51572 & 42.0 & & Level 7区8-10 & 5303 & 4.3 \\
\hline \multirow[t]{3}{*}{ REDL } & Affluent & 40609 & 33.1 & & & & \\
\hline & Medium & 40371 & 32.9 & & & & \\
\hline & Poor & 41685 & 34.0 & & & & \\
\hline
\end{tabular}

Table 2 Interactions of MR and REDL on SES, SC and NEPHSU. 


\begin{tabular}{|lllllll|}
\hline Variables & \multicolumn{3}{l}{ Intra-province $(\mathrm{M} \pm \mathrm{SD})$} & \multicolumn{4}{l|}{ Inter- province $(\mathrm{M} \pm \mathrm{SD})$} \\
\cline { 2 - 7 } & Affluent & Medium & Poor & Affluent & Medium & Poor \\
\hline Education & $2.57 \pm$ & $2.51 \pm$ & $2.36 \pm$ & $2.25 \pm$ & $2.26 \pm$ & $2.23 \pm$ \\
& 0.960 & 0.940 & 0.978 & 0.888 & 0.916 & 0.894 \\
household & $1.20 \pm$ & $1.42 \pm$ & $1.83 \pm$ & $1.12 \pm$ & $1.58 \pm$ & $2.22 \pm$ \\
income & 0.830 & 0.973 & 1.289 & 0.774 & 1.182 & 1.794 \\
\hline CSC & $3.87 \pm$ & $3.70 \pm$ & $3.84 \pm$ & $3.04 \pm$ & $3.66 \pm$ & $3.48 \pm$ \\
& 2.091 & 2.065 & 2.080 & 1.942 & 2.060 & 2.039 \\
SSC & $2.71 \pm$ & $2.57 \pm$ & $2.56 \pm$ & $2.39 \pm$ & $2.38 \pm$ & $2.43 \pm$ \\
& 1.766 & 1.740 & 1.732 & 1.615 & 1.640 & 1.672 \\
\hline ANEPHS & $0.67 \pm$ & $0.62 \pm$ & $0.65 \pm$ & $0.57 \pm$ & $0.59 \pm$ & $0.61 \pm$ \\
& 0.469 & 0.468 & 0.478 & 0.495 & 0.491 & 0.488 \\
\hline EHR & $0.37 \pm$ & $0.31 \pm$ & $0.36 \pm$ & $0.27 \pm$ & $0.29 \pm$ & $0.31 \pm$ \\
& 0.483 & 0.463 & 0.480 & 0.447 & 0.454 & 0.452 \\
\hline
\end{tabular}

Note: Education, CSC, SSC, ANEPHS and EHR were used as grade variables.

\section{Results of univariate analysis}

The results of cross-table analysis show (Table 3 ) that gender, education, community type, MR and REDL all have significant impacts on outcome variables. ANEPHS and EHR of group female, highly educated, urban communities, intra-province, and poor areas were all higher. $\operatorname{ANEPHS}\left(X^{2}=2807.538, p<0.001\right)$ and $\operatorname{EHR}\left(X^{2}=2224.646, p<0.001\right)$ increased with CSC grade, ANEPHS $\left(X^{2}=4980.274, p<0.001\right)$ and $\operatorname{EHR}\left(X^{2}=3501.905, p<0.001\right)$ also increased with CSC grade. The independent sample t-test showed that family income and residence time also had significant effects on ANEPHS and EHR respectively.

Table 3 Results of cross-table analysis, ANEPHS and EHR as the outcome variables, gender, education, community type, migration range, and REDL as the independent variables. 


\begin{tabular}{|c|c|c|c|c|c|}
\hline \multirow[t]{2}{*}{ Variables } & \multirow[t]{2}{*}{ Subgroups } & \multicolumn{2}{|l|}{ ANEPHS } & \multicolumn{2}{|l|}{ EHR } \\
\hline & & Rate (\%) & $x^{2}$ & Rate (\%) & $x^{2}$ \\
\hline \multirow[t]{2}{*}{ Gender } & Male & 60.9 & $80.077 * \star \star$ & 30.8 & $92.752^{\star \star \star}$ \\
\hline & Female & 63.5 & & 33.4 & \\
\hline \multirow[t]{4}{*}{ Education (year) } & $\leq 6$ & 53.0 & $1533.622^{\star \star \star}$ & 27.9 & 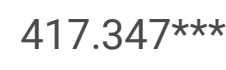 \\
\hline & $7-9$ & 60.7 & & 31.3 & \\
\hline & $10-12$ & 65.9 & & 33.2 & \\
\hline & $\geq 12$ & 70.6 & & 37.1 & \\
\hline \multirow[t]{2}{*}{ Community type } & Urban & 63.8 & $410.111^{\star \star \star}$ & 33.3 & 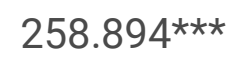 \\
\hline & Rural & 57.3 & & 28.3 & \\
\hline \multirow[t]{2}{*}{ Migration range } & Intra-province & 64.6 & $416.643^{\star \star \star}$ & 34.5 & $465.836^{\star \star \star}$ \\
\hline & Inter- province & 58.8 & & 28.7 & \\
\hline \multirow[t]{3}{*}{ REDL } & Affluent & 61.9 & $71.082^{\star \star \star}$ & 31.8 & $147.333^{\star \star \star *}$ \\
\hline & Medium & 60.9 & & 30.8 & \\
\hline & Poor & 63.7 & & 34.2 & \\
\hline
\end{tabular}

Note: ${ }^{* \star} p<0.001,{ }^{*} p<0.01{ }^{*} p<0.05$. The same is true of the symbols in the rest of the table.

\section{An analysis of the interactions among MR, REDL, SC and NEPHSU}

In order to further explore the interaction between MR, REDL, SC and IMs' PBS, we took CSC and SSC as the abscess axis, and rate of ANEPHS and EHR as the vertical axis to draw the variation trend diagrams of group intra-province (black solid line) and group inter-provincs (red dotted line) (Figure 1-4). The results showed that there are obvious differences between the two curves in different regions. On the whole, the two curves are always closest to each other in the group medium, while the two curves are furthest apart in the group affluent.

\section{Results of multivariate analysis}

The interaction between MR, REDL and SC had a significant impact on ANEPHS (Table 3). After introducing CSC, SSC, and interactions, Block 2 compared with Block 1, Omnibus test $\mathrm{X}^{2}$ increased by 5665.075 ( $p<0.001)$, Cox \& Snell $R^{2}$ increased from 0.014 to 0.062 , Hosmer \& Lemeshow test $X^{2}$ increased from 22.582 to 25.972 . According to OR value analysis, after controlling for other variables, interprovincial migration ( $O R=0.822)$ and medium $R E D L(O R=0.845)$ had a negative effect on ANEPHS. The main effects of $\mathrm{CSC}(\mathrm{OR}=1.124)$ and $\mathrm{SSC}(\mathrm{OR}=1.256)$ on ANEPHS were significant and positive. 
Among the four groups of interaction, only SSC * Poor* inter-province was not significant, and the OR values of the other three interactions were all significantly greater than 1 .

Table 3 Logistic regression results of gender, education, community type, residence duration, MR, REDL and SC on ANEPHS.

\begin{tabular}{|c|c|c|c|c|c|c|c|}
\hline \multirow{3}{*}{$\begin{array}{l}\text { Independent Variables } \\
\text { Gender Female }\end{array}$} & \multirow{3}{*}{$\begin{array}{l}\text { Reference } \\
\text { group }\end{array}$} & \multicolumn{3}{|l|}{ Block 1} & \multicolumn{3}{|l|}{ Block 2} \\
\hline & & \multirow{2}{*}{$\begin{array}{l}\text { OR } \\
1.122^{\star \star \star}\end{array}$} & \multicolumn{2}{|c|}{$95 \% \mathrm{Cl}$} & \multirow{2}{*}{$\begin{array}{l}\text { OR } \\
1.196^{\star \star \star}\end{array}$} & \multicolumn{2}{|c|}{$95 \% \mathrm{Cl}$} \\
\hline & & & 1.096 & 1.149 & & 1.168 & 1.225 \\
\hline Education $>9$ years & $\leq 9$ years & $1.249 * \star \star$ & 1.232 & 1.265 & $1.108^{\star \star \star}$ & 1.093 & 1.123 \\
\hline Community type Rural & Urban & $0.845^{\star \star \star}$ & 0.822 & 0.868 & $0.918 * \star \star *$ & 0.892 & 0.944 \\
\hline Household income & & $1.015^{\star \star}$ & 1.004 & 1.025 & $0.982^{\star \star \star}$ & 0.972 & 0.993 \\
\hline Residence duration & & $0.997 *$ & 0.995 & 0.999 & $0.991 * \star \star$ & 0.989 & 0.993 \\
\hline $\begin{array}{l}\text { Migration range Inter- } \\
\text { province }\end{array}$ & $\begin{array}{l}\text { Intra- } \\
\text { province }\end{array}$ & $0.835^{\star \star \star}$ & 0.815 & 0.856 & $0.822 * \star \star$ & 0.792 & 0.852 \\
\hline Medium & Affluent & $0.906^{* \star *}$ & 0.880 & 0.933 & $0.845^{\star \star \star}$ & 0.814 & 0.877 \\
\hline Poor & & 1.026 & 0.995 & 1.058 & 1.000 & 0.963 & 1.038 \\
\hline $\csc$ & & & & & $1.124^{\star \star \star}$ & 1.116 & 1.132 \\
\hline SSC & & & & & $1.256^{\star \star \star}$ & 1.245 & 1.267 \\
\hline $\begin{array}{l}\text { CSC * Medium* Inter- } \\
\text { province }\end{array}$ & & & & & $1.016 *$ & 1.001 & 1.030 \\
\hline $\begin{array}{l}\text { CSC * Poor* Inter- } \\
\text { province }\end{array}$ & & & & & $1.025^{\star \star}$ & 1.009 & 1.041 \\
\hline $\begin{array}{l}\text { SSC * Medium* Inter- } \\
\text { province }\end{array}$ & & & & & $1.053^{* \star *}$ & 1.031 & 1.075 \\
\hline $\begin{array}{l}\text { SSC * Poor* Inter- } \\
\text { province }\end{array}$ & & & & & 0.993 & 0.972 & 1.015 \\
\hline Omnibus test $\mathrm{X}^{2}$ & & 2128.821 & & & 7793.897 & & \\
\hline Cox \& Snell $\mathrm{R}^{2}$ & & 0.017 & & & 0.062 & & \\
\hline
\end{tabular}

The interaction of MR, REDL and SC had a significant impact on EHR (Table 4). Block 2 compared with Block 1, Omnibus test $X^{2}$ increased by 4476.847 ( $\left.p<0.001\right)$, Cox \& Snell $\mathrm{R}^{2}$ increased from 0.009 to 0.045 , Hosmer \& Lemeshow test $X^{2}$ decreased from 44.903 to 36.100 . According to OR value analysis, after controlling for other variables, interprovincial migration (OR=0.755) and medium REDL $(O R=0.806)$ had a negative impact on EHR, while CSC $(O R=1.110)$ and SSC $(O R=1.205)$ had significant and positive main 
effects on EHR, and the interactions of all four groups were significant. OR values of CSC * Medium* Inter- province, CSC * Poor* Inter- province, and SSC * Medium* Inter- province were significantly greater than 1 , while OR value of SSC * Poor* Inter- province was smaller than 1.

Table 4 Logistic regression results of gender, education, community type, residence duration, MR, REDL and SC on EHR.

\begin{tabular}{|c|c|c|c|c|c|c|c|}
\hline \multirow[t]{2}{*}{ Independent Variables } & \multirow{2}{*}{$\begin{array}{l}\text { Reference } \\
\text { group }\end{array}$} & \multicolumn{3}{|l|}{ Block 1} & \multicolumn{3}{|l|}{ Block 2} \\
\hline & & $O R$ & $95 \% \mathrm{Cl}$ & & $O R$ & $95 \% C$ & \\
\hline Gender Female & Male & $1.121 * \star \star$ & 1.094 & 1.148 & $1.190 * \star \star$ & 1.161 & 1.220 \\
\hline Education $>9$ years & $\leq 9$ years & $1.121^{\star \star \star}$ & 1.106 & 1.136 & 0.997 & 0.983 & 1.012 \\
\hline Community type Rural & Urban & $0.840 * * *$ & 0.816 & 0.865 & $0.908^{* * *}$ & 0.881 & 0.935 \\
\hline Household income & & $0.982^{\star \star *}$ & 0.972 & 0.993 & $0.951 * * *$ & 0.940 & 0.962 \\
\hline Residence duration & & $1.002^{*}$ & 1.000 & 1.004 & $0.996 * * *$ & 0.994 & 0.998 \\
\hline $\begin{array}{l}\text { Migration range Inter- } \\
\text { province }\end{array}$ & $\begin{array}{l}\text { Intra- } \\
\text { province }\end{array}$ & $0.799 * * *$ & 0.779 & 0.820 & $0.755^{\star \star \star}$ & 0.727 & 0.784 \\
\hline Medium & Affluent & $0.884^{\star * \star}$ & 0.858 & 0.912 & $0.806 * \star \star$ & 0.776 & 0.837 \\
\hline Poor & & $1.067 * \star *$ & 1.034 & 1.101 & 1.024 & 0.987 & 1.063 \\
\hline $\csc$ & & & & & $1.110 * \star \star$ & 1.102 & 1.117 \\
\hline SSC & & & & & $1.205^{\star \star \star}$ & 1.195 & 1.215 \\
\hline $\begin{array}{l}\text { CSC * Medium* Inter- } \\
\text { province }\end{array}$ & & & & & $1.021 * *$ & 1.006 & 1.035 \\
\hline $\begin{array}{l}\text { CSC * Poor* Inter- } \\
\text { province }\end{array}$ & & & & & $1.052^{\star \star \star}$ & 1.036 & 1.068 \\
\hline $\begin{array}{l}\text { SSC * Medium* Inter- } \\
\text { province }\end{array}$ & & & & & $1.063^{* * *}$ & 1.043 & 1.084 \\
\hline $\begin{array}{l}\text { SSC * Poor* Inter- } \\
\text { province }\end{array}$ & & & & & $0.972^{\star \star}$ & 0.953 & 0.992 \\
\hline Omnibus test $\mathrm{X}^{2}$ & & 1165.179 & & & 5642.026 & & \\
\hline Cox \& Snell $\mathrm{R}^{2}$ & & 0.009 & & & 0.045 & & \\
\hline
\end{tabular}

\section{Discussion}

There were three main findings: (1) The socioeconomic status (SES) and social capital (SC) of interprovincial IMs were significantly lower than those of intra-provincial IMs, and the gap was most 
prominent in affluent areas. (2) From low to high, the NEPHSU of inter-provincial IMs was ranked as affluent, medium and poor, while the corresponding order of intra-provincial IMs was medium, poor and affluent areas, and the gap of NEPHSU between inter-provincial and intra-provincial IMs was the largest in affluent areas. (3) SC could significantly promote the IMs' NEPHSU, but there was a gap between interprovincial and intra-provincial IMs, and the gap was the largest in affluent areas.

The household registration status still affects and determines the urban class structure and social integration to a large extent [37]. Despite the government's great efforts in recent years, the urbanization of people and the citizens of the migrant population has not been truly realized, and the social and economic conditions between the registered population and migrant population as well as within the migrant population are highly heterogeneous [34]. This study confirmed the hypothesis that there are significant differences in SES within the migrant population, and these differences were influenced by the interaction of MR and REDL. Data showed that inter-provincial migrants were indeed at a worse disadvantage than intra-provincial migrants in affluent areas, with lower scores for both education and family income. However, the picture was very different in medium and poor areas, where the family income of inter-provincial migrants exceeded that of intra-provincial migrants, although their average education level was still lower. Therefore, we believe that the situation of inter-provincial migrants in affluent areas is more difficult, while that of inter-provincial migrants in medium and poor areas may not be so bad.

As pointed out by Palloni et al. [18] that migration means a loss of the original social network and a reduction of social participation in the new environment. Previous study [31] has pointed out that the SC of migrant population is inferior to that of local people, but no research has explored the gaps among subgroups within the IMs. We found this gap and it was influenced by the interaction of MR and REDL. On the whole, the SC of the inter-provincial migrants was lower than that of the intra-provincial migrants, and this gap was the largest in the affluent areas. This trend is basically consistent with the abovementioned trend of SES, which supports the credibility of this study conclusion. Dialect, customs and culture vary widely among provinces in China, so intra-provincial migrants in a given province have an advantage in social adaptation and social network construction compared to inter-provincial migrants. Therefore, intra-provincial migrants have a higher level of SC than inter-provincial migrants. At the same time, we also noticed that the variation trend of SC with REDL was different between the inter-provincial group and the intra-provincial group, and these complex interaction relationships need to be explored by further studies.

We agree with the point that NEPHSU of the inter-provincial IMs is lower $[9,10,13-15]$, but we do not support the view that the NEPHSU level of the IMs in the affluent region is lower [12-15]. Compared with the existing studies, we have three differences: (1) Regional classification based on per capita GDP; (2) Three cities, Beijing, Tianjin and Shanghai, were excluded; (3) The interaction between MR and REDL was considered. We found that the trend of NEPHSU level changing with REDL was different between the inter-provincial and intra-provincial migrants. The former ranks (from low to high) affluent, medium and poor in the order of NEPHSU level in three regions, while the latter ranks medium, affluent, and poor. Of 
particular concern is that the gap in NEPHSU of IMs between the inter-provincial and intra-provincial groups was the largest in affluent regions. Due to China's financial transfer payment system, with the financial support of the central government, the density of grassroots health service resources and the per capita supply of NEPHS in medium and poor areas are higher than those in rich areas [38]. Some studies attributed the lack of NEPHS for IMs in affluent areas to this $[9,15]$. We believe that service supply may have an impact, but it is not enough to explain the phenomenon of higher NEPHSU level among IMs in affluent provinces. The lack of enthusiasm of the migrant population to participate in the NEPHS is also a significant factor [3], as evidenced by the fact that the EHR is much lower than ANEPHS, because the EHR is a voluntary program [5].

Although some studies have pointed out that SC can promote the utilization of health services [18-20, 39], there has been no consensus on this [40]. SC may be more salient for the health and well being of certain sub-populations and in particular contexts [33]. Uphoff et al. [32] have pointed out that the relationship between SC and health is moderated by SES, but the direction of regulation may be enhanced or weakened. This study suggests that SC has a significant positive promoting effect on NEPHSU by the IMs, but this promoting effect is moderated by the combination of MR and REDL. As we can see from the line chart, the distance between the dotted and the solid line is always the largest in the affluent group and the smallest in the medium group, which indicates that the relationship between SC and NEPHSU was significantly different with different MR and REDL. On the whole, even though the SES and SC of the inter-provincial migrants were lower, they still benefit more from SC when utilizing NEPHS, regardless of the type of region. This is in line with the first case proposed by Uphoff et al. [32], that is, a more significant social capital benefit on the health of disadvantaged persons in society, and no effects or limited health benefits for those in positions higher up in the social ladder.

Two things have to be pointed out. First of all, the selection of SSC measurement content in this study has strong Chinese cultural characteristics, such as homecoming associations, Party branch of the Chinese Communist Party and Communist Youth League, etc., which is difficult to find counterparts in the research based on other cultures, which may affect the comparability of different research conclusions to a certain extent. Secondly, because of China's NEPHS system of transfer payments, the cost of NEPHS in economically developed areas is mostly borne by themselves, while the cost of NEPHS in economically underdeveloped areas is mostly borne by the central government. As a result, NEPHS resources in poor areas are more abundant than those in rich areas. Such a situation may not be applicable in other developing countries.

\section{Conclusions}

This study reveals that the IMs' SES, SC and NEPHS utilization were influenced by MR and REDL. REDL can significantly affect the gaps of SES and SC among subgroups of IMs with different MR. Interprovincial migrants in affluent areas have relatively lower SES and SC, which may be a major barrier to their access to NEPHS, and the government should pay special attention to this vulnerable group when promoting equalization of NEPHS for IMs. 


\section{Abbreviations}

ANEPHS

Awareness of National Essential Public Health Services

CMDS

China Migrant Dynamic Survey

CSC

Cognitive Social Capital

EHR

Establishment of Health Records

IMs

Internal Migrants

MR

Migration Range

NEPHS

National Essential Public Health Services

NEPHSU

National Essential Public Health Services utilization

$\mathrm{NHC}$

National Health Commission

REDL

Regional Economic Development Level

SC

Social Capital

SES

Socioeconomic Status

SSC

Structural Social Capital

\section{Declarations}

\section{Acknowledgments}

The authors thank the Migrant Population Service Center, National Health Commission of the People's Republic of China for providing the data.

\section{Funding}

No.

\section{Availability of data and materials}


Since the data used in this paper were provided by the Migrant Population Service Center, which is the top agency governing migrant population issues in China, we had to sign a legally binding agreement with the agency that we will not share any original data with any third parties. However, interested researchers can apply for access to the data at http://www.ldrk.org.cn/.

\section{Authors' contributions}

All authors participated in the design of the study. ZY carried out the statistical analysis and composed the first draft. $\mathrm{CHJ}$ gave opinions for modification. All authors read and approved the final manuscript.

\section{Ethics approval and consent to participate}

The "National Internal Migrant Dynamic Monitoring Survey, 2017" data is publicly available to authorized researchers who have been given permission by the Migrant Population Service Center, and written informed consents were obtained from all participants. The analysis of public access data was exempted by the local IRB; as this involved analyzing de-identified existing data, ethical approval was not required.

\section{Consent for publication}

Not applicable.

\section{Competing interests}

No competing interests in this study.

\section{References}

1. China Migrant Population Development Report 2018. Beijing: China Population Press. 2019.

2. Li J, Nikolas Rose. Urban social exclusion and mental health of China's rural-urban migrants - A review and call for research. Health \& Place. 2017; 48 (2017): 20 - 30.

3. Yang X. Difference in utilization of basic public health service between registered and migrant population and its related factors in China,2015.Chin J Public Health. 2018; 34(10):781-785. doi:10.11847/zgggws 1115819 .

4. Gong P, Liang S, Carlton EJ , et al. Urbanisation and health in China. The Lancet. 2012; 379(9818): $843-852$.

5. National Code of Essential Public Health Services (Third Edition). 2017. http://www.nhc.gov.cn/ jws/s3578/201703/ d20c37e23e1f4c7db7 b8e25 f34473e1b.shtml. Accessed 15 Mar 2017.

6. Program of pilot work on equalization of basic public services in health and household planning for migrant population. http://www.nhc.gov.cn/ldrks/s3577/201312/39f344bd0a4f419ca66ef8b933eaa561.shtml. Accessed 19 Dec 2013. 
7. The State Council. Interim Regulations on Residence Permits. http://www.gov.cn/zhengce/201512/14/ content_5023611. htm. Accessed 14 Dec 2015.

8. NHC. Action Plan on Health Education and Promotion for the Migrant Population (2016-2020). http://www. nhc.gov.cn/ldrks/s3577/201606/cf593583b37241a58068e0aa0b86d2de.shtml. Accessed 14 June 2016.

9. Zhang J, Lin S, Liang D, et al. Public health services utilization and its determinants among internal migrants in China: evidence from a nationally representative survey. International Journal of Environmental Research and Public Health. 2017; 14(9):1002.

10. Guo J, Shao F, Fan H, et al. Analysis on the access to the basic public health care services and influencing factors among migrants.Chinese Journal of Health Policy. 2016; 9(8): 75-82.

11. Guo MD , Zhu Z, Dong TY, et al. Provincial and Age Disparity on Chronic Disease Education Among Migrants in China: The Migrants Population Dynamic Monitoring Survey. INQUIRY: The Journal of Health Care Organization, Provision, and Financing. 2019; 56. doi: 1177/0046958019895897.

12. Yan Q, Tong L. Utilization of basic public health services and its influence factors among young migrants. Chin J Public Health. 2019; 35(6): 680-684.

13. Yin Q, Xu QL.Establishment of health records and its influencing factors among migrant populations. Chin J Public Health. 2018; 34(10): 1351-1355.

14. Zhang L, Zhou CC. Acquisition of tuberculosis knowledge and its relevant factors among intraprovincial and inter-provincial migrant populations in China. Chin J Public Health. 2019; 35(2):147152.

15. Wei Y. Supply and utilization of health service among migrant population in China: a comparative study. Chin J Public Health. 2021; 37(2): 219-223.

16. Kawachi I, Subramanian SV, Kim D. SC and health. New York: Springer Science + Business Media, LLC; 2008.

17. Derose, KP. SC: What's it good for? Exploring the relationship between community social structure and access to health care. Los Angeles: University of California. 2003. (Dissertation)

18. Palloni A, Massey DS, Ceballos $M$, et al. SC and international migration: A test using information on family networks. American Journal of Sociology. 2001; 106(5): 1262 - 1298.

19. Deri C. Social networks and health service utilization. J Health Econ. 2005; 24: 1076 - 107.

20. Devillanova C. Social networks, information and health care utilization: Evidence from undocumented immigrants in Milan. Journal of Health Economics. 2008; 27 (2008): 265 - 286.

21. Jin L, Wen M, Fan JX, et al. Trans-local ties, local ties and psychological well-being among rural-tourban migrants in Shanghai. Social. Sci. Med. 2012; 75 (2): 288 - 296.

22. Hoi CK, Chen W, Zhou F, et al. The association between social resources and depressive symptoms among Chinese migrants and non-migrants living in Guangzhou, China. J. Pac. Rim Psychol. 2015; 9 (2): $120-129$. 
23. Du HF, Li XM, Lin DH. Individualism and sociocultural adaptation: Discrimination and SC as moderators among rural-to-urban migrants in China. Asian journal of social psychology. 2016; 18 (2): $176-181$.

24. Zhu YK, Gao JL, Nie X, et al. Associations of individual SC with subjective well-being and mental health among migrants: a survey from fifive cities in China. Int Health. 2019; 11, Suppl.1: 64 - 71.

25. Xiao Y, Miao SY, Sarkar C. Social ties, spatial migration paradigm, and mental health among two generations of migrants in China. Popul Space Place. 2020; e2389.

26. Guo J, Yang HL, Liu LL, et al. Status quo and determinants of awareness on basic public health service among migrant population. Chin J Public Health. 2019; 35(1): 63 - 66.

27. Song LJ, Chang TY. Do resources of network members help in help seeking? SC and health information search. Social Networks. 2012; 34 (2012): 658 - 669.

28. Hou ZY, Lin S, Zhang D. SC, neighbourhood characteristics and utilisation of destination public health services among domestic migrants in China: a cross sectional study. BMJ OPEN. 2017; 7: e014224. doi:10.1136/bmjoPHEn-2016-014224.

29. Zeng CB, Li XM, Du HF, et al. Experiences of stigma and health service utilization among young ruralto-urban migrants in China: the mediation role of SC. Vulnerable children and youth studies. 2020; 15(2): 97-109.

30. Palmer NA, Perkins DD. SC and community participation among migrant workers in China. Journal of community psychology. 2011; 39(1): 89 - 105.

31. Lu Y, Ruan DC, Lai GN. SC and economic integration of migrants in urban China. Social Networks. 2013; 35 (2013): 357 - 369.

32. Uphoff EP, Pickett KE, Cabiese B, et al. A systematic review of the relationships between SC and socioeconomic inequalities in health: a contribution to understanding the psychosocial pathway of health inequalities. International Journal for Equity in Health. 2013; 12(1):54.

33. Carpiano RM, Moore S. So What's Next? Closing Thoughts for this Special Issue and Future Steps for SC and Public Health. Soc Sci Med. 2020; doi.org/10.1016/j.socscimed.2020.113013.

34. Cheng F, Li SZ, Yue ZS. Socioeconomic Status and Mental Health among Laborers in Urban China: A Comparative Study of Native and Non-native Residents.Population \& Economics. 2018; (6): 42-52.

35. Chen Z, Carol A. Crawford G. The role of geographic scale in testing the income inequality hypothesis as an explanation of health disparities. Social. Sci. Med. 2012; 75(2012): 1022-1031.

36. Moore S, Carpiano RM. Measures of personal SC over time: A path analysis assessing longitudinal associations among cognitive, structural, and network elements of SC in women and men separately. Soc Sci Med. 2020; doi: 10.1016/j.socscimed.2019.02.023.

37. Lu YL. Does hukou still matter? The household registration system and its impact on social stratification and mobility in China.Social Sciences in China. 2008; (2): 56-75.

38. China health statistical digest 2018. Beijing: Peking Union Medical College Press,2018. 
39. Pennington JR, Oglesby WH, Alemagno Sonia. Impact of SC on the Availability of Health Care Services.[J]. Population health management. 2020. doi: 10.1089/pop.2020.0142.

40. Drose KP, Varda DM. SC and health care access: A systematic review. Med Care Res Rev. 2009; 66(3): 272-306. doi:10.1177/1077558708330428.

\section{Figures}

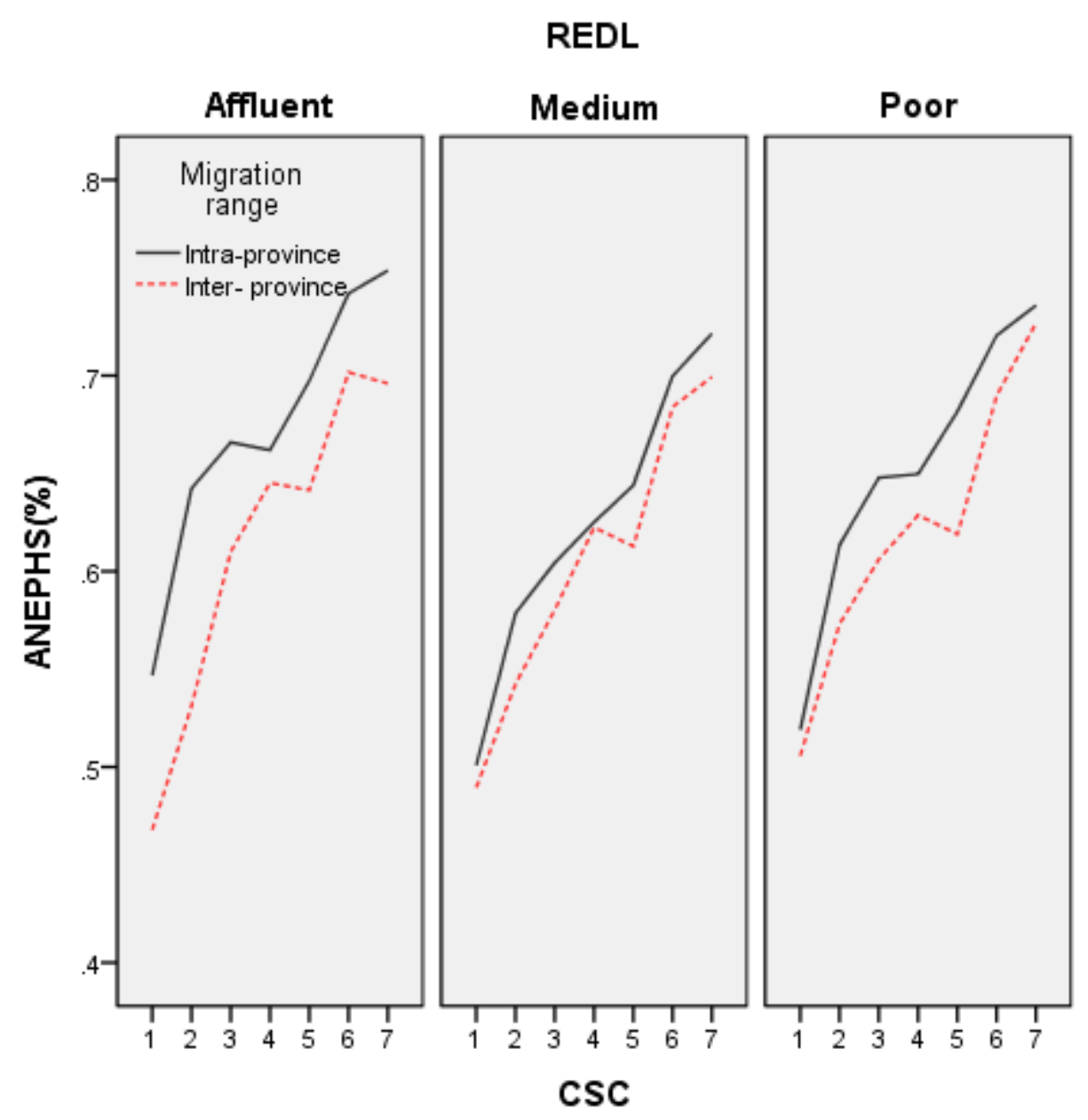

Figure 1

Interaction of MR, REDL, and CSC on ANEPHS. 


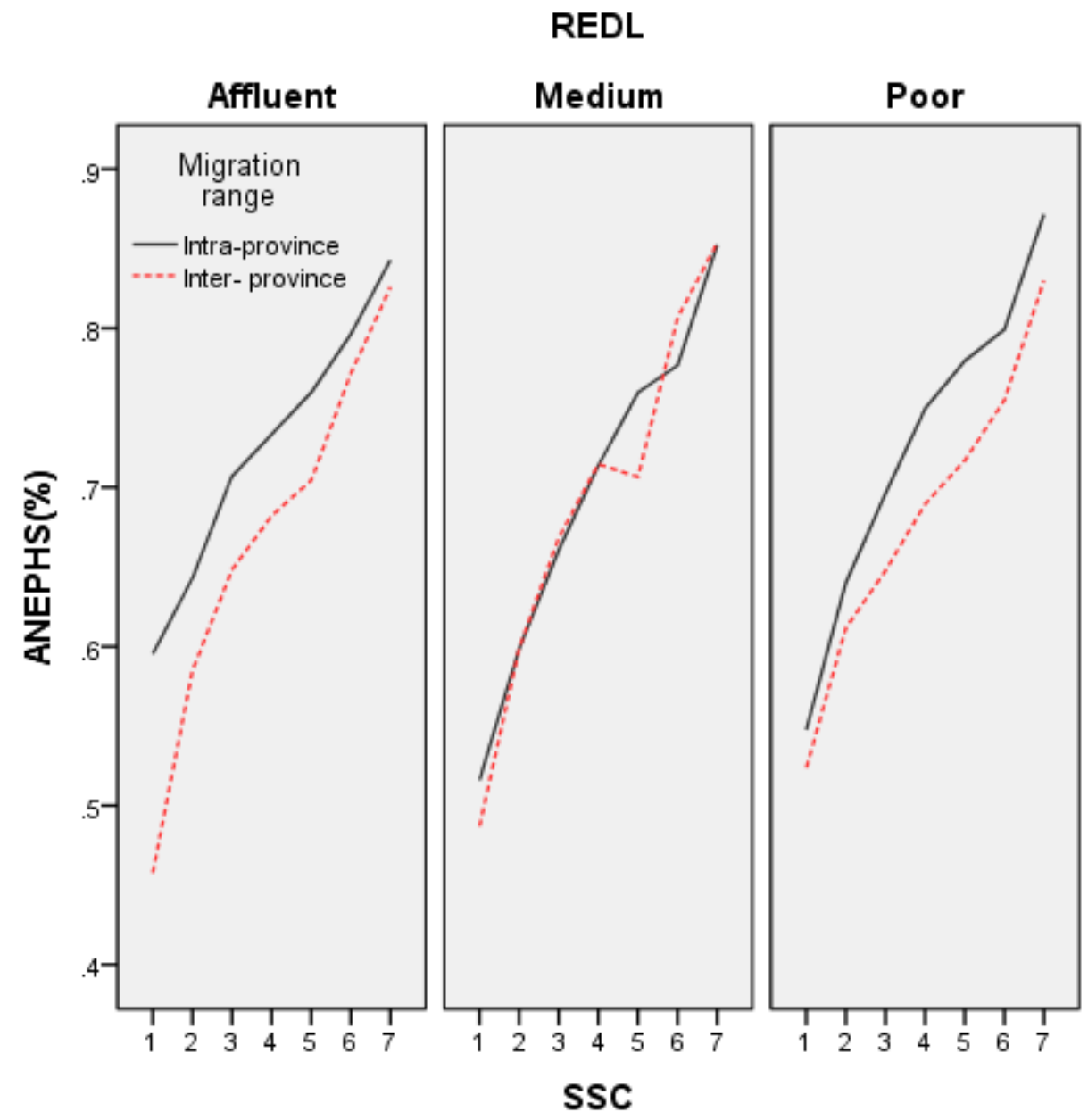

Figure 2

Interaction of MR, REDL, and SSC on ANEPHS. 


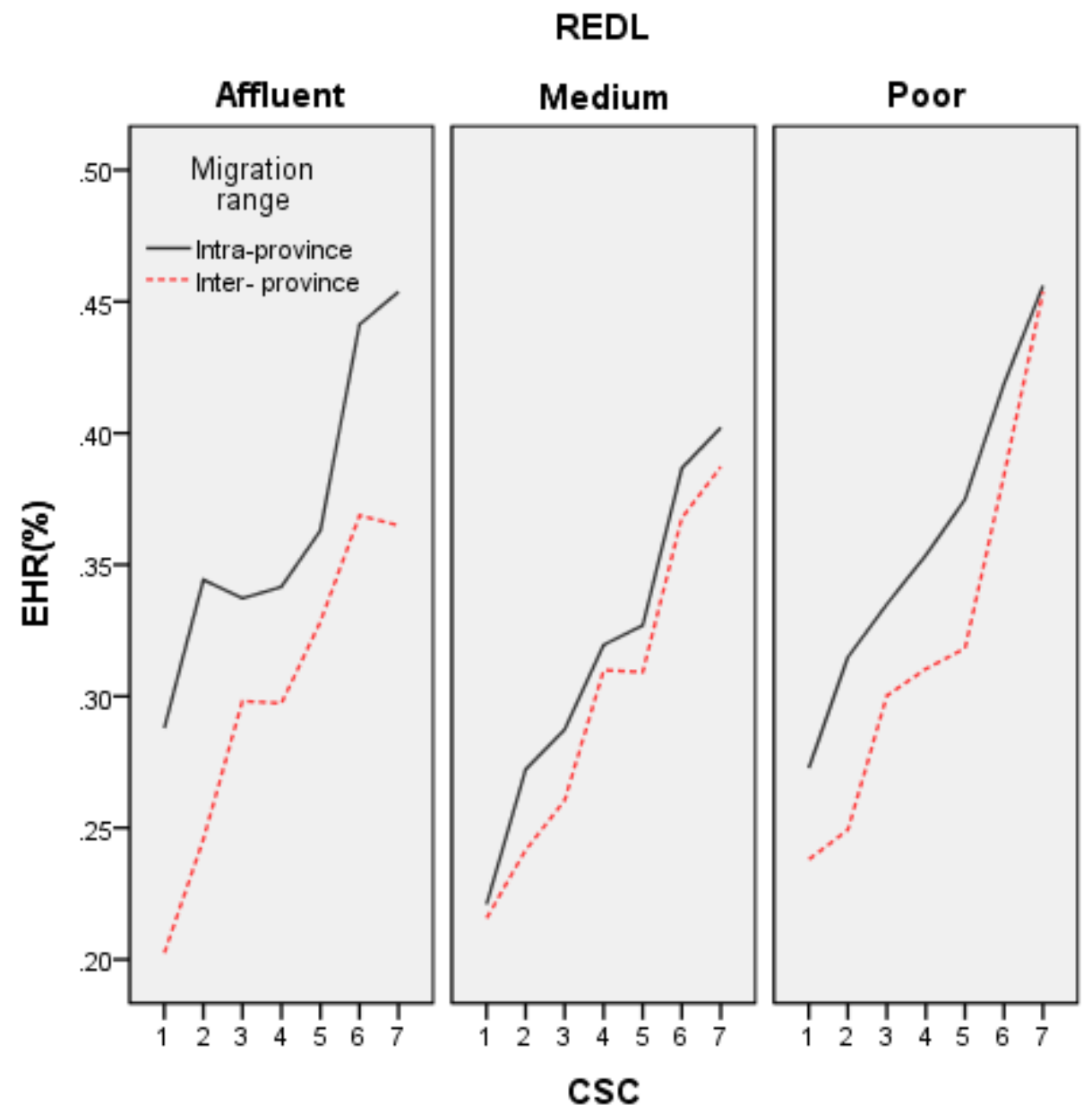

Figure 3

Interaction of MR, REDL, and CSC on EHR. 


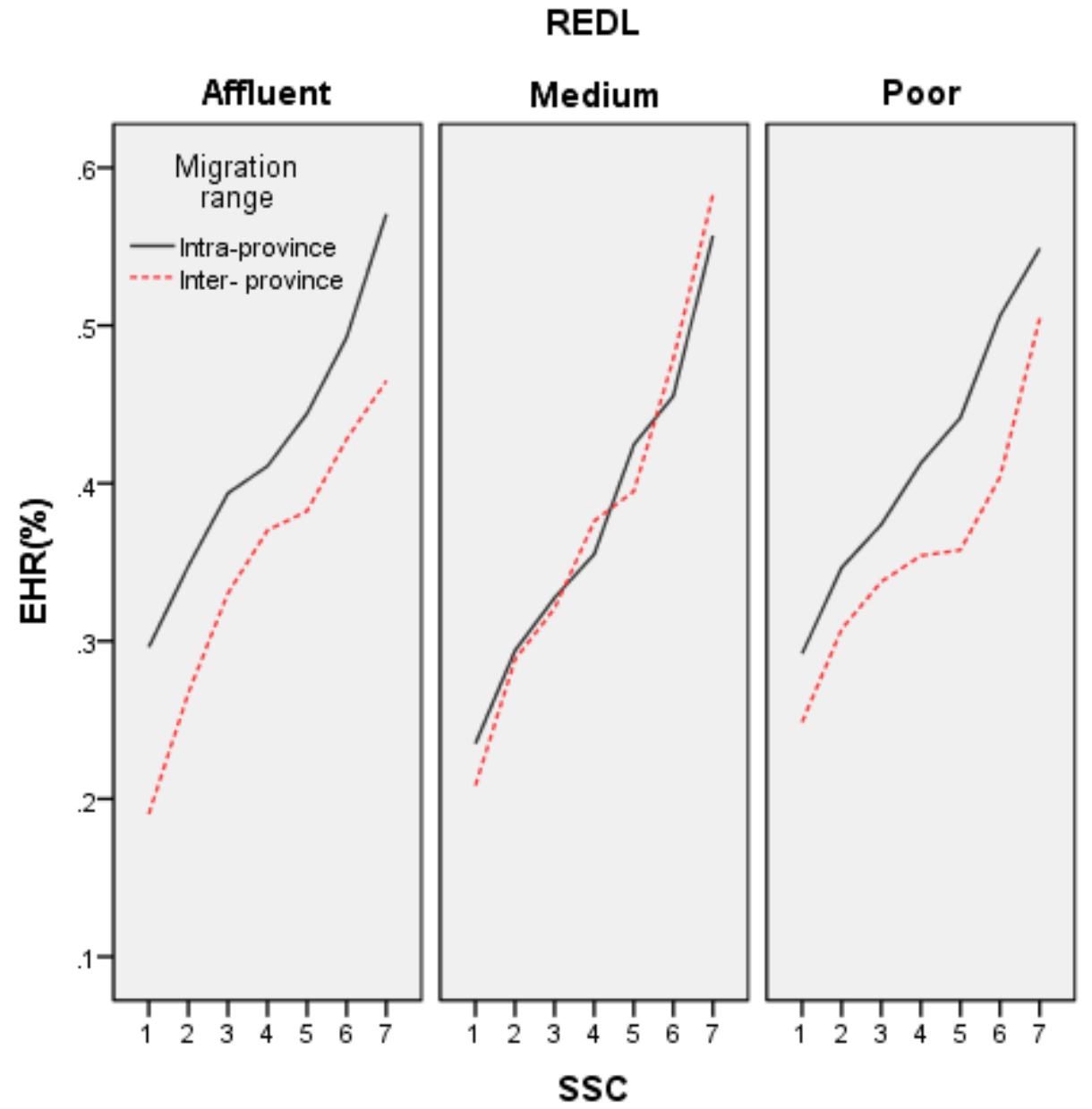

Figure 4

Interaction of MR, REDL, and SSC on EHR. 